\title{
COMPARATIVE STUDY OF ONE DIMENSIONAL AND TWO DIMENSIONAL STEADY SURFACE FLOW ANALYSIS
}

\author{
Laxmi Bhakta Maharjan ${ }^{1}$, Narendra Man Shakya ${ }^{2}$ \\ ${ }^{1}$ Department of Civil Engineering, Advanced College of Engineering and Management, Kupondole, Lalitpur, \\ Nepal \\ Email Address: laxmibhakta.maharjan@acem.edu.np \\ ${ }^{2}$ Department of Civil Engineering, Institute of Engineering, Pulchwok Campus, Lalitpur, Nepal
}

\begin{abstract}
Determination of actual water surface is required for design of hydraulic structures, reservoirs, flood plain management, and flood forecasting. Classical approach of analyzing the river flow using one dimensional flow analysis cannot provide the accurate information of water surface for different return period floods. So, both 1D and 2D steady surface flow analysis in prismatic channel and non-prismatic channel were done using models like HEC-RAS, FESWMS-2DH, GIS, and HECGEORAS to compare the results and recommended to select the best among these two flow analyses. Analysis of result showed that in prismatic channel, the water surface elevations obtained from 1D and 2D steady flow analysis for discharge $\mathrm{Q}=10 \mathrm{cft} / \mathrm{s}$ were almost similar with maximum variation of $0.33 \mathrm{ft}$. But in case of non-prismatic channel, the results of water surface elevations from 1D and 2D steady flow analysis for discharge $Q=5000 \mathrm{cft} / \mathrm{s}$ and $9430 \mathrm{cft} / \mathrm{s}$ were not similar and the maximum variation of $1.36 \mathrm{ft}$ and $1.75 \mathrm{ft}$ were found for two discharges respectively. 1D steady flow analysis is acceptable for prismatic channel except at bend which may require 2D analysis. But flow in non-prismatic channel requires 2D steady flow analysis for precise water surface elevation.
\end{abstract}

Keywords: Surface Flow Analysis, Steady flow, $1 D$ Flow, 2D-Flow, HEC-RAS, FESWMS-2DH, GIS, and HEC-GEORAS

\section{Introduction}

An open channel is a conduit in which a liquid flows with a free surface. Open channel flow may be either steady or unsteady. Steady flow in open channel is said to occur when the flow properties such as the discharge at a section do not changes with time. If the change in flow condition with respect to time is a major, concern, then the open channel flow should be treated as unsteady. In most of the open channel problems it is necessary to study the flow behavior under steady conditions. Steady flow in an open channel system is termed as steady uniform flow when the depth is the same at every section of the channel. On the other hand, the flow is termed as steady varied flow when the depth of flow changes along the length of channel. Steady uniform flow is the fundamental type of flow treated in open channel hydraulics. Varied flow also may be either gradually or rapidly varying. In rapidly varying flow, the depth of flow changes abruptly over a comparatively short distance. Hydraulic jumps and the hydraulic drops are the examples of rapidly varied flows.

The hydraulic engineer's inevitable task in hydraulic design practices includes the computation of water surface profiles for an open channel. The computation is carried out for (a) the discharge in a channel with sub-critical or super-critical flow (b) determination of back water effect of a proposed hydraulic structure like dam, barrage, weir bridge etc and to design canals and transition zones (c) tracing of upstream flood levels with the channel improvement (d) establishing water surface profiles for levee design (e) establishing flooded area limits for flood insurance studies (f) determination of water surface elevation for flood plain management $(\mathrm{g})$ determination of areas inundated by various 
flood discharges for the assessment of damages (h) providing a reasonable initial condition from which an unsteady simulation can be started (i) determination of the safe and optimum operation of control structures and so on.

It is very much known that, Nepal is rich in water resources. Most of the rivers are the source of surface water for the development of hydropower, irrigation, water supply and other uses. Nepal is a country with high potential of hydropower development. Complete hydrological analysis is necessary for the development of these projects. Most of the Nepalese rivers are with large floodplains and with complicated geology of the river banks. We have heard and seen disasters caused by the high floods in recent past. Failure of civil structures like dams, weir, spillway, bridges etc; inundates the agriculture land and residential area, loss of property and life are some examples caused due to high floods. So, Detail study of the rivers is needed to know the impacts of the design floods before any projects are developed.

Classical approach of analyzing the river flow using one-dimensional flow analysis can provide some information about the flow behavior of the river for different return period floods. The entire physical phenomenon should be incorporated to get the detail information about the river flow. For this, complete two-dimensional flow analysis of river should be done

\section{Need of Research}

Surface flow is a complicate phenomenon. Flow pattern and impacts for different return period floods should be known before any hydraulic structures are constructed. Classical approach of determining the water surface profile, width of waterway, and scour depth for different return period floods cannot provide the satisfactory result. The empirical formula for waterway and scour depth derived for certain region may not be accurate to apply in other region because of difference in landscape, topography, and flow pattern. So, use of empirical formulae to know the hydraulic features of the river can mislead and design may fail causing the loss of property and life.

One dimensional flow analysis may not be sufficient for the surface water analysis due to the complicated hydraulic conditions at bridge crossings, and other civil structures like dam, weir, barrage etc.

Most the Terai Rivers of Nepal have large flood plains (more than kilometers). So, the use of empirical formula and one-dimensional flow analysis for these types of river flow cannot provide accurate results. The accuracy of high flood levels, rating curves and velocity profiles at a project site is important and depends upon the type of hydraulic analysis i.e. 1D or 2D and computer software. In Nepal, the 1D flow analysis by HEC-RAS is very common may be because of its simplicity. It is understood that 2D flow analysis will give accurate results than 1D. This research is needed to prove that 2D flow analysis is accurate than 1D. For this 1D and 2D hydraulic analysis software are used and results are compared.

\section{Objectives of Study}

The main objective of the research is to study one-dimensional and two-dimensional flow behavior of the channel using HEC-RAS (1D) and the Finite Element Surface-Water Modeling System: Two Dimensional Flow in Horizontal Plane (FESWMS-2DH) model.

The more specific objectives are as given bellows;

- To review available literatures related to steady state open channel flow analysis methods and models.

- To review the existing computer models that analyzes the steady flow problems. 
- One Dimension and Two Dimension Surface Flow Analysis of the natural and artificial channel (Prismatic and Non-Prismatic) for different floods.

- Comparison of results obtained from the two dimensional analysis with the results given by the one-dimensional analysis.

- To recommend the best analysis among one-dimensional and two-dimensional surface water analysis.

- To recommend/suggest about the result and its impact.

\section{Model}

1) Finite Element Surface Water Modeling System: Two Dimensional Flow in a Horizontal Plane (FESWMS-2DH)

2) HEC-RAS

3) GIS (With HEC-GEORAS)

Now a day, many computer programs have also been introduced for the computation of steady state water surface profiles. Among them HEC, with latest version of HECRAS (US Army Crops of Engineers, 1990) is one of the most frequently used computer programs. Most of the models introduced so far are used only for the computation of sub-critical flows and only a few models can be used for the computation of supercritical flows. Some of the existing models are incapable of computing flows when the flow regimes change from sub-critical to supercritical or vice versa. But, some of models like HECRAS and FESWMS-2DH are capable of handling such situation. Models based on energy equation use the empirical relationship to compute the eddy losses (expansion or contraction) due to the change in shape and size of the channel.

\section{Literature Review}

The computation of steady flow profiles basically involves the integration of the dynamic equation of the gradually varied flow. This takes the form as,

$$
\frac{d y}{d x}=\frac{S_{o}-S_{f}}{1-F^{2}}
$$

Where,

$\mathrm{S}_{\mathrm{o}}=$ Slope of channel bottom.

$\mathrm{S}_{\mathrm{f}}=$ Slope of the total energy line

$\mathrm{F}=$ Froude Number

Many methods have been developed so far. All of them can be grouped into four categories, such as, Direct Integration Method, Graphical method, Numerical integration method, and Computer programs. 


\section{Computer Programs on Steady Flow System}

Many computer programs are in existence to compute the steady flow profiles in natural or artificial channels. Eichert (1970) reviewed capabilities of six programs among the number of programs available. HEC-2 model for backward computation is one of the most frequently used computer programs in North America (Wisner et al., 1989). French (1985) reports that Computer program E431, developed by US Geological Survey, is theoretically similar to HEC-2 model. US Army Crops of Engineers (1995) introduced HEC-RAS as an improved version of HEC-2.

Some other models capable of simulating steady gradually varied flow are ICSS model (Manz, 1985), RIVER4 program (Smith and Ashenhurst, 1986), Washington State University Computer Program (Chaudhary and Schulte, 1986). These models are discussed in Finigan (1995).

Some of the computer programs commercially available and widely used and capable of computing the gradually varied steady flow in open channel system are discussed below.

\section{HECRAS/HEC 2}

The HEC-2 model (US Army Crops of Engineers, 1990) was developed to calculate water surface profiles for steady, gradually varied flows in both prismatic and non-prismatic channels. Both subcritical and super-critical flow profiles can be estimated and the effects of various obstructions such as bridges, culverts, weirs, and structures in over- bank region are considered.

HEC-RAS is an integrated package of hydraulic analysis programs, in which the user interacts with the system through the use of a Graphical User Interface (GUI). The system is capable of performing steady flow water surface profile calculations, and includes unsteady flow, sediment transport, and several hydraulic design computations.

In HEC-RAS terminology, a project is a set of data files associated with a particular river system. The modeler can perform any or all of the various types of analysis, included in the HEC-RAS package, as part of the project. The data files for a project are categorized as follows: plan data, geometric data, steady flow data, unsteady flow data, sediment data, and hydraulic design data.

During the course of a study the modeler may want to formulate several different plans. Each plan represents a specific set of geometric data and flow data. Once the basic data are entered into the HEC-RAS, the modeler can easily formulate new plans. After simulations are made the various plans, the results can be compared simultaneously in both tabular and graphical form.

HEC-RAS, as improved version of HEC-2, is an integrated system of software designed for interactive use in multi-tasking, multi-user network environment. One of the major features of HECRAS is that it can handle a full network of channels or a single river reach (US Army Crops of Engineers, 1995).

Both models are subjected to basic assumptions used for steady gradually varied flow. The original purpose of the HEC-2 model was to determine water surface elevations for specified discharge in natural channels to aid in the US Army Corps of Engineers flood plain management program (French, 1985). In this capacity, the model has been used:

- To determine areas inundated by various flood discharges for the assessment of damage.

- To study the effects of land use in flood plains from the viewpoint of flood damages.

- To study how flood damages can be mitigated by various channel improvements.

It is noted that the computer program HEC-2 model originated from a step backwater program written in WIZ (a version of BASIC). Bill S. Eichert originally developed it in the Hydraulic Engineering 
Center (HEC) in 1984. In 1966 the first FORTRAN version of HEC-2 was released. In response to a high demand from the practitioners, the HEC implemented HEC-2 for MS-DOS compatible microcomputers (PC) in 1984. The programs were modified in 1986 to meet FORTRAN 77 standards. The 1988 version of HEC-2 was created with a number of added features, with an emphasis on hydraulic design applications. The 1990 version includes some more error corrections to the 1988 version plus culvert hydraulics. HEC-RAS was released in 1995.

Both HEC-RAS and HEC-2 model are based on the standard step method. It is an iterative procedure used to calculate an unknown water surface at a cross-section.

HEC-RAS has other optional capabilities too; it includes multiple profile analysis; multiple plan analysis; optional friction loss equations; cross section interpolation; mixed flow regime calculation; modeling stream junctions; and flow distribution calculations.

But, HEC-RAS cannot analyze the flow with distributed lateral inflows and outflows, due to the limitations of the form of equations used in modeling. User has to select the contraction or expansion loss coefficients.

\section{MIKE 11}

MIKE 11 is a Microcomputer -Based Modeling System for Rivers and Channels. MIKE 11 was developed by Danish Hydraulic Institute for the simulation of flows, water levels and transport of sediment and dissolved or suspended materials. MIKE 11 is a general purpose microcomputer-based model that simulates not only rainfall-runoff processes, but also river hydraulics, sediment transport, and water quality. MIKE 11 can be used in design, management, an operation of river systems and channel networks.

MIKE 11 is based on the Danish Hydraulic Institute program system 11, which provides a similar set of modeling system capabilities for the mainframe environment.

The MIKE 11 model consists of several individual modules, allowing the user to add specific models for various types of hydrological simulation as the need for these features arises in the application. The model is menu-driven. It is configured with a core component termed the basic module plus a series of other add-on modules. The basic module includes the menu portion that deals with data handling an program execution; a catchment database that includes river cross-section data; a database for rainfall time series and water level and discharge data; computational modules for rainfall-runoff simulation and for river flow; and a module that permits plotting of input and output data.

The catchment and stream channel network system is modeled by the rainfall-runoff module. Complex river systems can be simulated. Runoff computations are based on a lumped-conceptual type model that continuously accounts for the moisture content in four storage zones: (1) surface storage, (2) lower zone storage, (3) upper ground water storage, and (4) lower groundwater storage. Runoff to stream channels is assumed to consist of overland flow, interflow, and base flow. The river flow module permits the use of a variety of computational procedures. The full non-linear one-dimensional unsteady-flow equations are normally used, while simplified channel routing equations (kinematic wave or diffusion wave equations) can be employed as deemed suitable in specific parts of the full model. Complex channel configurations can be accommodated, including looping channels. Channel computations can also include lateral discharges, free and submerged flow at weirs, flooding an drying of overflow areas, flow over embankments, and two - dimensional flood-plain flows. Culverts and other stream structures can also be simulated. Irregular cross-section geometry can be used, flowrelated roughness and local head losses can be employed, and the model can deal with both subcritical and super-critical flow conditions. 
Required data are the catchment and river data module include hydrological parameters, river cross sections, floodplain topography, and discharge and water level records. For the rain database, either measured rainfall time series data or synthesized rainfall time series are required.

\section{Finite Element Surface Water Modeling System (FESWMS-2DH)}

FESWMS-2DH is a modular set of computer programs developed to simulate surface-water flow where the flow is essentially two-dimensional in a horizontal plane. The programs that comprise the modeling system have been designed specifically to analyze flow at bridge crossings where complicated hydraulic conditions exist, although the programs can be used to model many other types of steady and unsteady surface-water flows. Three separate, but interrelated, programs form the core of the modeling system: (1) The Data Input Module (DINMOD), (2) the Depth-Averaged Flow Module (FLOMOD), and (3) the Analysis of Output Module (ANOMOD).

The primary purpose of DINMOD is to generate a two- dimensional finite element network (grid). Functions performed by this program include editing of input data, automatic generation of all or part of the finite element network, refinement of an existing network, ordering of elements to enable an efficient equation solution, and graphic display of the finite element network. As such, DINMOD acts as a preprocessor of the finite element network (grid) data. Processed network data can be stored in a data file for use by other FESWMS-2DH programs.

FLOMOD simulates both steady and unsteady (time-dependent) two-dimensional (in a horizontal plane) surface-water flow. The program numerically solves the vertically integrated equations of motion and continuity, using the finite element method of analysis, to obtain depth-averaged velocities and flow depths. The effects of bed friction and turbulent stresses are considered, as are, optionally, surface wind stresses and the Coriolis force. Flow over weirs, or weir-type structures (such as highway embankments), and flow through culverts can also be modeled. The computed twodimensional flow data can be written to a data file and stored for future use.

Results of flow simulations are presented graphically and in the form of reports by ANOMOD. Plots of velocity and unit-flow vectors; ground-surface and water-surface elevation contours; and timehistory graphs of velocity, unit flow, or stage (water-surface elevation) at a computation point can be produced. As such, ANOMOD acts as a postprocessor in the modeling system.

\section{Methodology}

\subsection{Governing Equations}

The equations that govern the hydrodynamic behavior of an incompressible fluid are based on the classical concepts of conservation of mass and momentum. For many practical surface-water flow applications, knowledge of the full three-dimensional flow structure is not required, and it is sufficient to use mean- flow quantities in two perpendicular horizontal directions.

Equations that describe depth-averaged two-dimensional flow are presented in this section. Additional equations that are used to model special cases of one-dimensional flow through bridges and culverts and one-dimensional flow over weirs and highway embankments are described. Initial and boundary conditions needed to solve the set of governing equations are also discussed. 


\subsubsection{Depth-Averaged Flow Equations}

The depth-averaged velocity components in the horizontal $\mathrm{x}$ and $\mathrm{y}$ coordinate directions, respectively, are defined as:

$$
\begin{aligned}
& \mathrm{U}=\frac{1}{H} \int_{b}^{Z_{b+H}} u \mathrm{dz} \\
& \mathrm{V}=\frac{1}{H} \int_{b}^{Z_{b+H}} v \mathrm{dz}
\end{aligned}
$$

Where, $\mathrm{H}$ is the water depth; $\mathrm{z}$ is the vertical direction; $\mathrm{z}_{\mathrm{b}}$ is the bed elevation; $\mathrm{u}$ is the horizontal velocity in the $\mathrm{x}$ - direction at a point along the vertical coordinate: and $\mathrm{v}$ is the horizontal velocity in the $\mathrm{y}$ - direction at a point along the vertical coordinate. The depth-averaged surface-water flow equations are derived by integrating the three-dimensional conservation of mass and momentum equations with respect to the vertical co-ordinate from the bed to the water surface, assuming that vertical velocities and accelerations are negligible. The vertically-integrated momentum equations are

$$
\begin{gathered}
\frac{\partial}{\partial t} \mathrm{HU}+\frac{\partial}{\partial x}\left(\beta_{\mathrm{uu}} \mathrm{HUU}\right)+\frac{\partial}{\partial y}\left(\beta_{\mathrm{uv}} \mathrm{HUV}\right)+\mathrm{gH} \frac{\partial Z_{b}}{\partial x}+\frac{1}{2} \mathrm{~g} \frac{\partial H^{2}}{\partial x}-\Omega H V+\frac{1}{\rho}\left[\tau_{x}^{b}-\tau_{x}^{s}-\frac{\partial}{\partial x}\left(\mathrm{H} \tau_{\mathrm{xx}}\right)-\right. \\
\left.\frac{\partial}{\partial y}\left(\mathrm{H} \tau_{\mathrm{xy}}\right)\right]=0
\end{gathered}
$$

in the $\mathrm{x}$ direction, and

$$
\begin{gathered}
\frac{\partial}{\partial t} \mathrm{HU}+\frac{\partial}{\partial x}\left(\beta_{\mathrm{uv}} \mathrm{HVU}\right)+\frac{\partial}{\partial y}\left(\beta_{\mathrm{vv}} \mathrm{HVV}\right)+\mathrm{gH} \frac{\partial Z_{b}}{\partial y}+\frac{1}{2} \mathrm{~g} \frac{\partial H^{2}}{\partial y}+\Omega H V+\frac{1}{\rho}\left[\tau_{y}^{b}-\tau_{y}^{s}-\frac{\partial}{\partial x}\left(\mathrm{H} \tau_{\mathrm{xy}}\right)-\right. \\
\left.\frac{\partial}{\partial y}\left(\mathrm{H} \tau_{\mathrm{yy}}\right)\right]=0
\end{gathered}
$$

in the y direction, and the continuity (conservation of mass) equation is

$$
\frac{\partial}{\partial t} \mathrm{H}+\frac{\partial}{\partial x}(\mathrm{HU})+\frac{\partial}{\partial y}(\mathrm{HV})=0
$$

where, $\beta_{\mathrm{uu}} \beta_{\mathrm{uv}}, \beta_{\mathrm{vu}}$ and $\beta_{\mathrm{vv}}$ are momentum correction coefficients that account for the variation of velocity in the vertical direction; $g$ is gravitational acceleration; $\Omega$ is the Coriolis parameter; $\rho$ is the density of water, which is assumed constant; $\tau_{x}^{b}$ and $\tau_{y}^{b}$ are bottom shear stresses acting in the $\mathrm{x}$ and $\mathrm{y}$ directions, respectively; $\tau_{x}^{s}$ and $\tau_{y}^{s}$ are surface shear stresses acting in the $\mathrm{x}$ and $\mathrm{y}$ directions, respectively; and $\tau_{x x}, \tau_{x y}, \tau_{y x}$ and $\tau_{y y}$ are shear stresses caused by turbulence where, for example, $\tau_{x y}$ is the shear stress acting in the $\mathrm{x}$ direction on a plane that is perpendicular to the $\mathrm{y}$ direction.

\subsection{Simulation}

The collected and generated topographic and hydraulic data were used in both one and twodimensional analysis. 


\subsubsection{One Dimensional Analysis}

Using GIS with HEC-GEORAS the river channel with cross data at different chainage was generated and exported to the HEC-RAS. Two different cases were studied, one was artificial prismatic channel and other one was natural stream. Both cases were analyzed as one-dimensional flow in HECRAS for different discharges.

In case of prismatic channel, the water surface elevation, velocity and water depth were studied for different discharges $(10 \mathrm{cft} / \mathrm{s}$ to $70 \mathrm{cft} / \mathrm{s})$. For natural stream, the water surface elevation was studied for different discharges $(5000 \mathrm{cft} / \mathrm{s}$ and $9430 \mathrm{cft} / \mathrm{s})$.

\subsubsection{Two Dimensional Analysis}

The collected and generated data were used in FESWMS-2DH for two-dimensional analysis. All the hydrological and hydraulic data used were same as in the one-dimensional flow analysis. At the beginning of the model run, all the boundary conditions were set to zero (cold start). The result generated from the first run was used for second run and so on. The process was continued till the result converged.

The result generated from both one-dimensional and two-dimensional analysis were tabulated and analyzed.

\section{Result and Discussion}

The results of water surface elevations, velocity and water depths at various discharges for prismatic channels obtained from the one and two-dimensional analysis were used for comparative study between one-dimensional and two-dimensional analysis. The water surface elevations, velocities and water depths were obtained for seven different discharges $(10 \mathrm{cft} / \mathrm{s}$ to $70 \mathrm{cft} / \mathrm{s})$ and all results were used for the comparative study.

But in case of non-prismatic channels, only water surface elevations were studied for two different discharges (5000 cft/s and $9430 \mathrm{cft} / \mathrm{s})$.

\subsection{Comparison of One-Dimensional Results with Two Dimensional Results}

\subsubsection{Prismatic Channel (90 Degree Bend)}

The results obtained from the one-dimensional surface water analysis using HERAS and Twodimensional surface water analysis using FESWMS-2DH showed that there are slightly differences in water surface elevations (i.e water depths) and velocities at different chainages. The maximum difference in water surface elevation of $0.33 \mathrm{ft}$ is found at chainage $146.38(\mathrm{ft})$ for the discharge of 20 $\mathrm{cft} / \mathrm{s}$. The maximum variation in velocity of $39.45 \%$ at chainage $189.22(\mathrm{ft})$ for discharge of $10 \mathrm{cft} / \mathrm{s}$. But in other cases, the variations in water surface elevations and velocities are less significant. The velocities, only in the direction of flow were obtained from one-dimensional analysis using HECRAS. But in two-dimensional analysis from the FESWMS-2DH velocity distribution in both directions were obtained. The comparison of the results obtained from 1-D and 2-D analysis are made in the following tables and figures.

\subsubsection{Non Prismatic Channel (Natural Stream)}

The results obtained from the one-dimensional surface water analysis using HERAS and two dimensional surface water analysis using FESWMS-2DH showed that there are slightly differences in water surface elevations at different chainages. The maximum difference in water surface elevation of $1.36 \mathrm{ft}$ for the discharge of $5000 \mathrm{cft} / \mathrm{s}$ at chainage $664.882(\mathrm{ft})$ and of $1.75 \mathrm{ft}$ for the discharge of $9430 \mathrm{cft} / \mathrm{s}$ is found. Other than this, the variation in results obtained from one-dimensional and two- 
dimensional analysis not much significant except at downstream. The variation will be more if the higher flood discharges are considered. The water surface elevation results obtained from twodimensional analysis are lower than results obtain from the one-dimensional analysis.

Table 1 Comparative Study of 1-D and 2-D Analysis of Prismatic Channel for Discharge $(\mathrm{Q}=10 \mathrm{cft} / \mathrm{s})$

\begin{tabular}{|c|c|c|c|c|c|c|c|c|c|c|c|}
\hline \multirow[b]{2}{*}{ 息 } & \multicolumn{5}{|c|}{ 2-D } & \multicolumn{3}{|c|}{ 1-D } & \multirow[b]{2}{*}{ 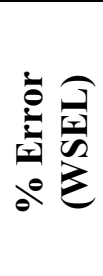 } & \multirow[b]{2}{*}{ 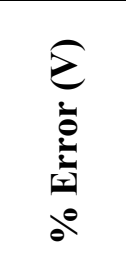 } & \multirow{2}{*}{ 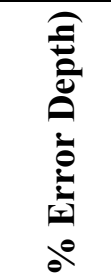 } \\
\hline & $\underbrace{a}_{\vec{D}}$ & $\sum_{\vec{b}}^{\infty}$ & $\underset{\theta}{E}$ & 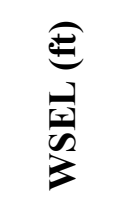 & $\underbrace{\infty}_{i}$ & $\begin{array}{l}\underset{\Xi}{E} \\
\stackrel{\Xi}{0} \\
\stackrel{0}{0}\end{array}$ & 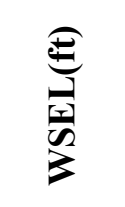 & $\stackrel{E}{E}$ & & & \\
\hline 0.00 & 0.00 & -0.21 & 1.82 & 101.82 & 0.21 & 1.55 & 101.55 & 0.29 & 0.26 & -36.79 & 14.60 \\
\hline 20.00 & 0.00 & -0.21 & 1.82 & 101.82 & 0.21 & 1.55 & 101.55 & 0.29 & 0.26 & -35.51 & 14.60 \\
\hline 40.00 & 0.01 & -0.21 & 1.82 & 101.82 & 0.21 & 1.55 & 101.55 & 0.29 & 0.26 & -36.50 & 14.65 \\
\hline 55.00 & 0.01 & -0.21 & 1.82 & 101.82 & 0.21 & 1.55 & 101.55 & 0.29 & 0.26 & -36.72 & 14.65 \\
\hline 70.00 & 0.00 & -0.21 & 1.82 & 101.82 & 0.21 & 1.55 & 101.55 & 0.29 & 0.26 & -38.74 & 14.65 \\
\hline 80.00 & -0.01 & -0.21 & 1.82 & 101.82 & 0.21 & 1.55 & 101.55 & 0.29 & 0.26 & -36.70 & 14.69 \\
\hline 90.00 & 0.00 & -0.21 & 1.82 & 101.82 & 0.21 & 1.55 & 101.55 & 0.28 & 0.26 & -33.33 & 14.69 \\
\hline 97.84 & 0.03 & -0.21 & 1.82 & 101.82 & 0.21 & 1.55 & 101.55 & 0.29 & 0.26 & -36.52 & 14.65 \\
\hline 105.38 & 0.08 & -0.20 & 1.82 & 101.82 & 0.21 & 1.55 & 101.55 & 0.28 & 0.26 & -32.73 & 14.60 \\
\hline 115.01 & 0.11 & -0.18 & 1.82 & 101.82 & 0.21 & 1.55 & 101.55 & 0.29 & 0.26 & -38.65 & 14.65 \\
\hline 122.85 & 0.15 & -0.15 & 1.82 & 101.82 & 0.21 & 1.55 & 101.55 & 0.28 & 0.26 & -31.55 & 14.69 \\
\hline 130.70 & 0.18 & -0.11 & 1.82 & 101.82 & 0.21 & 1.55 & 101.55 & 0.29 & 0.26 & -35.37 & 14.65 \\
\hline 138.53 & 0.19 & -0.06 & 1.82 & 101.82 & 0.20 & 1.55 & 101.55 & 0.28 & 0.26 & -38.48 & 14.79 \\
\hline 146.38 & 0.19 & -0.06 & 1.82 & 101.82 & 0.20 & 1.55 & 101.55 & 0.29 & 0.26 & -43.42 & 14.79 \\
\hline 154.22 & 0.23 & -0.02 & 1.82 & 101.82 & 0.23 & 1.55 & 101.55 & 0.29 & 0.27 & -26.55 & 14.98 \\
\hline 164.22 & 0.15 & 0.16 & 1.81 & 101.81 & 0.22 & 1.55 & 101.55 & 0.29 & 0.25 & -32.23 & 14.17 \\
\hline 174.22 & 0.16 & -0.14 & 1.79 & 101.79 & 0.22 & 1.55 & 101.55 & 0.29 & 0.23 & -34.49 & 13.36 \\
\hline 189.22 & 0.14 & -0.15 & 1.80 & 101.80 & 0.21 & 1.55 & 101.55 & 0.29 & 0.24 & -39.45 & 13.65 \\
\hline 204.22 & 0.22 & 0.12 & 1.80 & 101.80 & 0.25 & 1.55 & 101.55 & 0.29 & 0.25 & -17.78 & 13.89 \\
\hline 224.22 & 0.22 & 0.01 & 1.47 & 101.77 & 0.22 & 1.55 & 101.55 & 0.29 & 0.22 & -34.02 & $\begin{array}{c}-5.30 \\
\end{array}$ \\
\hline 244.22 & 0.23 & 0.04 & 1.15 & 101.75 & 0.23 & 1.55 & 101.55 & 0.29 & 0.19 & -25.52 & -35.37 \\
\hline 264.22 & 0.23 & 0.04 & 1.64 & 101.64 & 0.24 & 1.55 & 101.55 & 0.29 & 0.09 & -23.20 & 5.37 \\
\hline 284.22 & 0.24 & 0 & 2.13 & 101.63 & 0.24 & 1.55 & 101.55 & 0.29 & 0.08 & -23.4 & 27.26 \\
\hline
\end{tabular}


Table 2 Comparative 1-D and 2-D Water Surface Analysis of Non-prismatic Channel

\begin{tabular}{|c|c|c|c|c|c|c|}
\hline \multirow[b]{3}{*}{ CHAINAGE } & \multicolumn{2}{|c|}{$\begin{array}{c}\text { Discharge } \\
(Q=5000 \mathrm{cft} / \mathrm{s})\end{array}$} & \multirow{3}{*}{$\begin{array}{c}\% \\
\text { DIFF(WSEL) }\end{array}$} & \multicolumn{2}{|c|}{$\begin{array}{c}\text { Discharge } \\
(Q=9430 \mathrm{cft} / \mathrm{s})\end{array}$} & \multirow{3}{*}{$\begin{array}{c}\% \\
\text { DIFF(WSEL) }\end{array}$} \\
\hline & 1-D & 2-D & & 1-D & 2-D & \\
\hline & WSEL(ft) & WSEL(ft) & & WSEL(ft) & WSEL(ft) & \\
\hline 0.00 & 89.79 & 89.65 & -0.15 & 91.04 & 90.79 & -0.28 \\
\hline 123.40 & 89.79 & 89.22 & -0.64 & 91.04 & 90.29 & -0.83 \\
\hline 194.70 & 89.79 & 89.19 & -0.67 & 91.04 & 90.16 & -0.98 \\
\hline 246.80 & 89.76 & 89.17 & -0.67 & 91.01 & 90.27 & -0.82 \\
\hline 376.38 & 89.70 & 89.03 & -0.75 & 90.94 & 90.23 & -0.79 \\
\hline 471.93 & 89.65 & 88.89 & -0.85 & 90.89 & 90.22 & -0.74 \\
\hline 503.96 & 89.62 & 88.85 & -0.86 & 90.85 & 90.22 & -0.70 \\
\hline 628.87 & 89.28 & 88.24 & -1.18 & 90.73 & 90.07 & -0.73 \\
\hline 664.88 & 89.45 & 88.09 & -1.55 & 90.69 & 90.01 & -0.76 \\
\hline 717.90 & 89.21 & 87.89 & -1.51 & 90.40 & 89.91 & -0.54 \\
\hline 790.15 & 88.87 & 87.71 & -1.32 & 90.02 & 89.81 & -0.23 \\
\hline 880.27 & 88.46 & 87.54 & -1.05 & 89.53 & 89.71 & 0.20 \\
\hline 881.80 & 88.46 & 87.54 & -1.05 & 89.53 & 89.71 & 0.20 \\
\hline 1060.83 & 87.80 & 87.44 & -0.41 & 89.13 & 89.37 & 0.26 \\
\hline 1238.82 & 87.14 & 87.32 & 0.21 & 88.74 & 88.58 & -0.18 \\
\hline 1270.55 & 87.02 & 87.30 & 0.32 & 88.67 & 88.56 & -0.12 \\
\hline 1399.19 & 86.95 & 87.19 & 0.28 & 88.57 & 88.47 & -0.11 \\
\hline 1558.57 & 86.86 & 87.04 & 0.22 & 88.45 & 88.35 & -0.11 \\
\hline 1567.72 & 86.85 & 86.95 & 0.11 & 88.44 & 88.35 & -0.11 \\
\hline 1719.10 & 86.94 & 86.90 & -0.05 & 88.55 & 88.29 & -0.29 \\
\hline 1824.01 & 86.86 & 86.87 & 0.01 & 88.47 & 88.22 & -0.28 \\
\hline 1969.11 & 86.75 & 86.68 & -0.08 & 88.37 & 88.05 & -0.36 \\
\hline 1977.53 & 86.74 & 86.67 & -0.09 & 88.36 & 88.05 & -0.35 \\
\hline 2112.45 & 86.58 & 86.50 & -0.09 & 88.22 & 88.09 & -0.15 \\
\hline 2195.16 & 86.48 & 86.47 & -0.01 & 88.14 & 87.95 & -0.22 \\
\hline 2239.29 & 86.47 & 86.45 & -0.02 & 88.12 & 87.94 & -0.20 \\
\hline 2356.42 & 86.43 & 86.38 & -0.06 & 88.08 & 87.78 & -0.34 \\
\hline 2388.85 & 86.42 & 86.35 & -0.08 & 88.07 & 87.77 & -0.35 \\
\hline
\end{tabular}




\begin{tabular}{|c|c|c|c|c|c|c|}
\hline 2475.66 & 86.39 & 86.29 & -0.11 & 88.04 & 87.72 & -0.37 \\
\hline 2586.66 & 86.35 & 86.21 & -0.16 & 88.00 & 87.65 & -0.40 \\
\hline 2612.67 & 86.34 & 86.19 & -0.17 & 87.99 & 87.60 & -0.45 \\
\hline 2691.52 & 86.29 & 86.14 & -0.18 & 87.96 & 87.43 & -0.60 \\
\hline 2776.94 & 86.24 & 85.99 & -0.29 & 87.93 & 87.38 & -0.62 \\
\hline 2814.64 & 86.23 & 85.93 & -0.35 & 87.92 & 87.36 & -0.64 \\
\hline 2960.99 & 86.19 & 85.85 & -0.40 & 87.87 & 87.42 & -0.52 \\
\hline 3006.99 & 86.08 & 85.82 & -0.30 & 87.79 & 87.43 & -0.41 \\
\hline 3076.94 & 85.91 & 85.69 & -0.26 & 87.69 & 87.33 & -0.41 \\
\hline 3083.15 & 85.90 & 85.67 & -0.27 & 87.68 & 87.32 & -0.41 \\
\hline 3190.16 & 85.79 & 85.49 & -0.35 & 87.59 & 87.25 & -0.39 \\
\hline 3295.39 & 85.69 & 85.24 & -0.53 & 87.51 & 87.03 & -0.55 \\
\hline 3332.38 & 85.65 & 85.23 & -0.49 & 87.48 & 86.99 & -0.57 \\
\hline 3512.14 & 85.52 & 85.20 & -0.38 & 87.36 & 86.78 & -0.67 \\
\hline 3588.79 & 85.47 & 85.13 & -0.39 & 87.31 & 86.73 & -0.67 \\
\hline 3647.14 & 85.41 & 85.09 & -0.38 & 87.28 & 86.69 & -0.68 \\
\hline 3779.14 & 85.29 & 85.08 & -0.24 & 87.22 & 86.89 & -0.38 \\
\hline 3879.15 & 85.19 & 85.01 & -0.21 & 87.17 & 86.81 & -0.42 \\
\hline 4052.20 & 85.16 & 84.81 & -0.41 & 87.14 & 86.67 & -0.54 \\
\hline 4148.21 & 85.14 & 84.68 & -0.54 & 87.12 & 86.14 & -1.14 \\
\hline 4219.39 & 85.13 & 84.59 & -0.64 & 87.11 & 85.84 & -1.48 \\
\hline 4244.21 & 85.12 & 84.55 & -0.68 & 87.10 & 85.60 & -1.75 \\
\hline 4367.21 & 85.10 & 84.61 & -0.57 & 87.09 & 85.30 & -2.09 \\
\hline 4410.20 & 85.09 & 84.63 & -0.55 & 87.09 & 85.24 & -2.18 \\
\hline 4539.79 & 85.09 & 84.67 & -0.50 & 87.08 & 85.01 & -2.43 \\
\hline 4555.02 & 85.08 & 84.68 & -0.47 & 87.07 & 85.01 & -2.43 \\
\hline
\end{tabular}




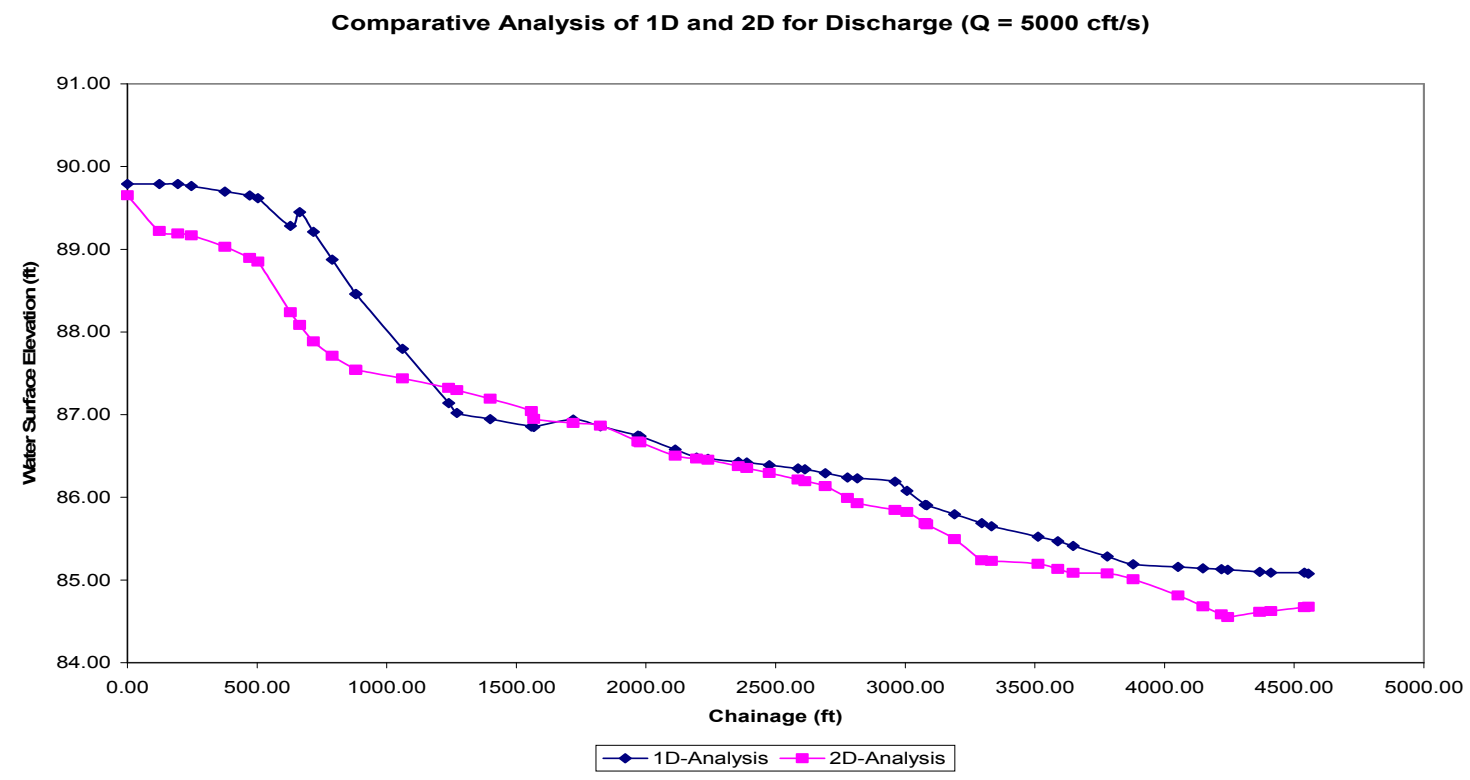

Fig 1 Comparison of 1D and 2D Results of Water Surface Profile of Non-prismatic Channel $(\mathrm{Q}=$ $5000 \mathrm{cft} / \mathrm{s})$

Comparative Analysis of 1D and 2D for Discharge ( $Q=9430 \mathrm{cft} / \mathrm{s})$

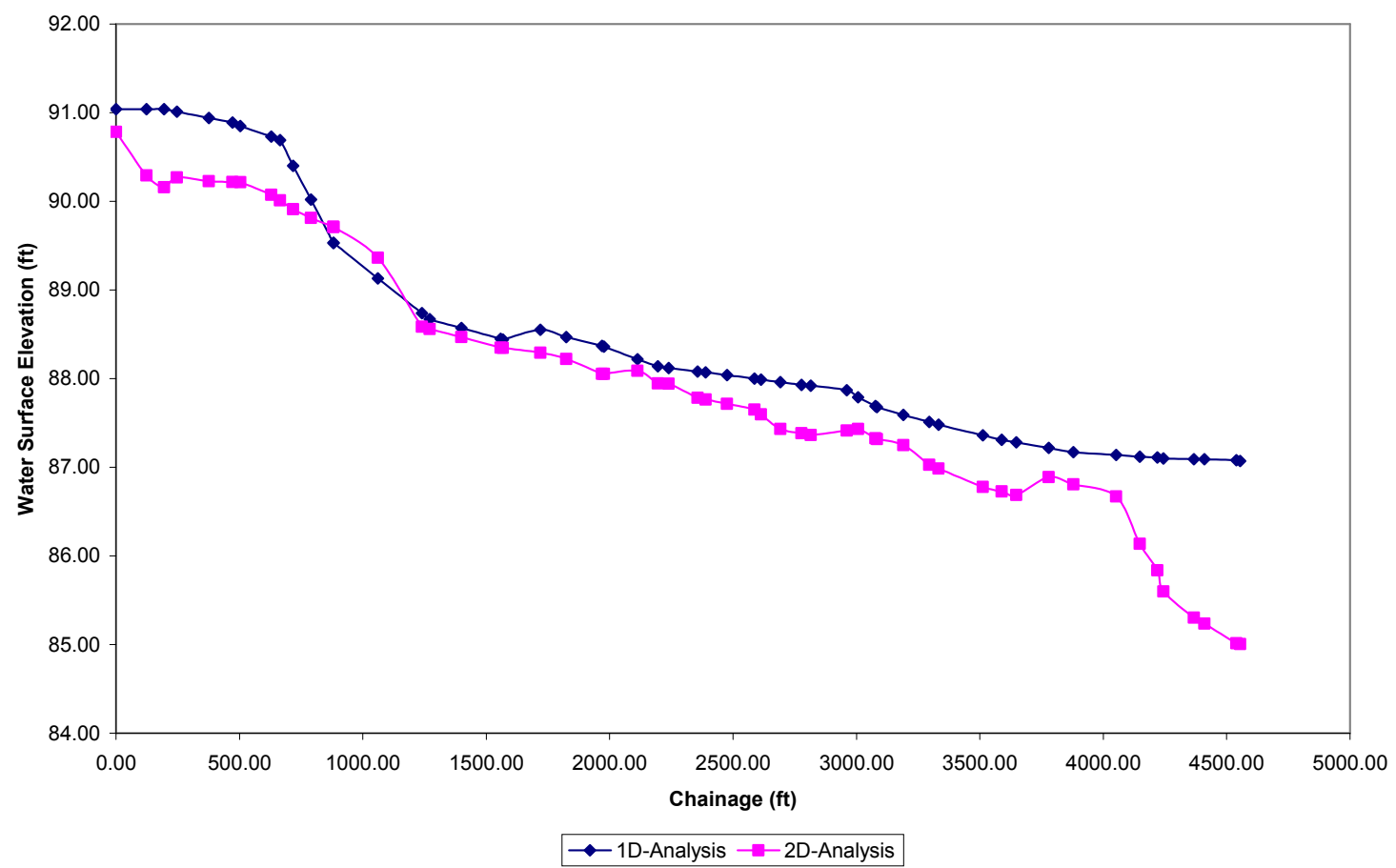

Fig 2 Comparison of 1D and 2D Results of Water Surface Profile of Non-prismatic Channel $(\mathrm{Q}=$ $9430 \mathrm{cft} / \mathrm{s})$ 


\section{Conclusion and Recommendation}

\subsection{Conclusion}

Various models that can be used for the steady flow in open channel system like HEC-RAS, MIKE11, HEC 2, and FESWMS-2DH were reviewed. The Theory of gradually varied steady flow in an open channel system was also reviewed in detail. The literatures in two-dimensional surface water analysis by different researchers were also reviewed.

For the comparative study of one-dimensional and two-dimensional surface flow analysis, two different models were formed. One of them was prismatic channel and another one was non-prismatic channel (natural stream). The required topographic and hydrological data were obtained. These data used to generate stream channel using GIS software with HEC-GEORAS. The generated stream channel was used in HEC-RAS for one-dimensional analysis. From the topographic data, complete finite element network design had been done for both prismatic and non-prismatic channels. The $\mathrm{x}, \mathrm{y}$ and $\mathrm{z}$ (bed elevations) data were generated from the finite element network design. These data were used in FESWMS-2DH for the analysis. Same hydraulic parameters such as Manning's coefficient value were used for both $1 \mathrm{D}$ and $2 \mathrm{D}$ analysis.

Considering the two different models, the results obtained from 1D and 2D analysis with the same inputs following conclusion can be drawn:

The water surface elevations, velocities and water depths obtained from the 1D and 2D analysis for prismatic are comparatively similar. There is slight variation in these parameters. The 1D analysis only provides the velocity in the direction of flow. But the 2-D analysis gives velocity in $\mathrm{x}$ and $\mathrm{y}$ directions which are very much important at the bend of the channel. The bend of the channel is the most critical part of the whole channel length. So, Velocity distributions in both directions are required for the structure design of the channel at bend. Therefore, for linear channel or, with slight bend, one dimensional analysis is enough for the study of surface profile and design of channel but higher bend complete two-dimensional analysis is must since two-dimensional analysis can provide the necessary velocity variations at the bend.

In case of non-prismatic channel like Natural River where the river width is large and bed level variation is non-uniform, two-dimensional analysis is necessary to study the actual flow behavior. The 1-D analysis also can provide a fair result for small discharges. But for large flood discharges, since, the variation of water surface elevations tends to increase by increasing the discharges, complete 2-D analysis is necessary to know the water surface elevations and other flow behaviors. For the economic and safe design of dam, and other hydraulic structure, where the flood plain is very large, actual level of surface water must be known. From these results it can be concluded that two-dimensional analysis is necessary for natural streams and one-dimensional analysis is sufficient in case of prismatic channel.

\subsection{Recommendations}

Both HECRAS and FESWMS - 2DH can stimulate the steady and non-steady flow in artificial as well as natural channels. These softwares can also stimulate the surface water near bridge, dam and other hydraulic structure. Sediment transport and scouring of bed materials also can be stimulated.

Following recommendations may be made for the further study of the flow behavior of the open channel flow in both prismatic and non prismatic channels. 
- In this research, Steady flow was considered in both prismatic and non-prismatic channels. For the future research work, unsteady flow in $1 \mathrm{D}$ and $2 \mathrm{D}$ can be considered to study the actual behavior of the open channel flow.

- Flow behavior near dam, bridge and other hydraulic structures for both steady and non-steady flow can be studied.

- For the design of hydraulic structures like dam, bridge, spur, levees, sediment and scour studies should be done. These studies can be done considering two dimensional flows for steady and non-steady flow.

- The research can be done considering the three dimensional flow for steady and non steady flows.

\section{References}

1. American National Standards Institute, "American National Standard Programming Language FORTRAN”, ANSI X3.9-1978, 1978

2. Arcement, G. J., and Schneider, V. R., "Guide for Selecting Manning's Roughness Coefficients for Natural Channels and Flood Plains", Federal Highway Administration Report No. FHWA-TS-84-204, 1984

3. Bakhmeteff, Boris A, "Hydraulic of Open Channels", McGraw-Hill Book Company Inc., New York, Ny,329pp,1932

4. $\quad$ Barnes, H. H., Jr., “Roughness Characteristics of Natural Channels”, U.S. Geological Survey Water-Supply Paper 1849, 1967

5. Bodhaine, G. L., "Measurement of Peak Discharge at Culverts by Indirect Measurements", U.S. Geological Survey Techniques of Water Resources Investigations, 1968

6. Bradley, J. N., "Hydraulics of Bridge Waterways (2nd ea.)", Federal Highway Administration Hydraulic Design Series, No.1, 1978

7. Buell, W. R., and Bush, B. A., "Mesh Generation -- A Survey", Transactions of the American Society of Mechanical Engineers, Journal of Engineering for Industry, ser. B., v. 95, no. 1, 1973

8. Chaudhary, M. Hanif and Schulte, Andreas M., "Computation of Steady State Gradually Varied Flows in Parallel Channels", Canadian Journal of Civil Engineering, Vol.13,pp 391986

9. Chow, V.T, "Open Channel Hydraulics", International Edition, McGraw-Hill Book Company, pp.217-231

10. Chow V.T, "Integrating the Equation of Gradually Varied Flow", Proc. ASCE Vol.81, Nov. 1955

11. Engelman, M. S., Strang, G., and Bathe, K. J., "The Application of Quasi-Newton Methods in Fluid Mechanics", International Journal for Numerical Methods in Engineering, v. 17, no. 5, 1981

12. Ezra A, "A Direct Step Method for Computing Water Surface Profiles", Trans. ASCE Vol.119, 1954 pp. 453-462 
13. Fischer, H. B., List, E. J., Koh, R. C. Y., Imberger, J., and Brooks, N. H., "Mixing in Inland and Coastal Waters", New York, Academic Press, 1979

14. Garratt, J. R., "Review of Drag Coefficients over Oceans and Continents", Monthly Weather Review, v. 105, no. 7, 1977

15. Henderson. F.M, “Open Channel Flow”, Macmillan Publishing Co. Inc., New York, NY, 522pp, 1966

16. Hicks, B. B., "Some Evaluations of Drag and Bulk Transfer Coefficients over Water Bodies of Different Sizes", Boundary-Layer Meteorology, v. 3, 1972

17. Hicks, B. B., Drinkrow, R. L., and Grauze, G., "Drag and Bulk Transfer Coefficients Associated with a Shallow Water Surface", Boundary-Layer Meteorology, v. 6, no. 1/2, 1974

18. Hood, P., "Frontal Solution Program for Unsymmetric Matrices", International Journal for Numerical Methods in Engineering, v. 10, no. 2, 1976

19. Jansen, P. P., Van Bendegom, L., Van den Berg, J., Devries, M., and Zanen, A., "Principles of River Engineering - The Non-Tidal Alluvial River", London, Pittman, 1979

20. King, I. P., and Norton, W. R., "Recent Applications of RMA's Finite Element Models for Two-Dimensional Hydrodynamics and Water Quality", in Brebbia, C. A., Gray, W. G., and Pinder, G. F, eds., Finite Elements in Water Resources, International Conference, 2nd, London, 1978, Proceedings, London, Pentech Press, 1978

21. Lee, J. K. and Froehlich, D. C., "Review of Literature on the Finite-Element Solution of the Equations of Two-Dimensional Surface-Water Flow in the Horizontal Plane”, U.S. Geological Survey Circular 1009, 1986

22. Manz, David H., "Newton Iterative Solution for the One-Dimensional Steady Spatially Varied Flow Equations Expressed in Finite Difference Form”, Research Report No. CE 85-7, Department of Civil Engineering, University of Calgary, 1985

23. Monoobe, Nagoho, "Back-Water and Drop-Down Curves for Uniform Channels", Transactions, American Society of Civil Engineers, Vol. 103, pp. 950-989, 1938

24. Prasad, R, "Numerical Method of Computing Flow Profile", Journal of Hydraulic Div. Proceedings of ASCE January 1970 pp. 75-86

25. Rodi, Wolfgang, "Hydraulics Computations with the k-E Turbulence Model",in Smith, P. E., ed., Applying Research to Hydraulic Practice, Conference of the Hydraulics Division of the American Society of Civil Engineers, Jackson, Miss, 1982 Proceedings, New York, American Society of Civil Engineers, 1982

26. Sokolnikoff, I. S., and Redheffer, R. M., "Mathematics of Physics and Modern Engineering (2nd ea.)”, New York, McGraw-Hill, 1966

27. Strang, G., and Fix, G. J., "An Analysis of the Finite Element Method, Englewood Cliffs", N.J., Prentice-Hall, 1973

28. U.S Department of Transportation, Federal Highway Administration; "Finite Element Modeling System: Two Dimensional Flow in Horizontal Plane”, User Manual, 1989

29. U.S Army Crops of Engineers, "HEC-RAS River Analysis System User's Reference Manual Hydrologic Engineering Center”, Davis, CA, 1995 
30. Wang, J. D., and Connor, J. J., "Mathematical Modeling of Near Coastal Circulation”, Cambridge, Mass., Massachusetts Institute of Technology, Department of Civil Engineering, Ralph M. Parsons Laboratory for Water Resources and Hydrodynamics, Report No. 200, 1975

31. Zienkiewicz, 0. C., "The Finite Element Method (3rd ed.)”, London, McGraw-Hill, 1977 